\title{
BRAGANÇA E A MARUJADA: PEDAÇOS DE IMANÊNCIA
}

\author{
Helane Súzia Silva dos Santos ${ }^{1}$ \\ Maria dos Remédios de Brito $^{2}$
}

A vida sussura...

(BRITO, M. R)

\section{1.}

O que a tradição da cultura popular importa ainda para os nossos dias de liquidação da vida e seus costumes culturais? Uma questão nos impõe com o trato dessa escrita-imagem. Como ritmar a cultura popular? Vivemos em uma era perturbadora, as pessoas estão conectadas por vidas que atravessam todos os dias os limites, os parâmetros de presença, de espaço, de tempo, de individualidade, de singularidade, que antes eram acolhedores para pensar a vida, a cultura... O presente está em mutação efetiva. Muitos se sentem perdidos, impactados, outros estão lançados na roda do agora, expostos diante de um presente que corre, sem freios e sem paradas. Estamos sem armas, encostados nas paredes, quase sem história, deslocados, sobressaltados diante de determinadas situações.

Nesse milênio, estamos expostos a coordenadas que lançam a vida para certas extremidades, um esvaziamento dos valores, um gozo imediato deslizando pelo corpo desorientado. Há um alimento sombrio que atravessa a máquina produtiva de nossos dias, uma mistura de horror e esperança, mas parece que essa maquinação subjetiva conserva o capital sem problemas. $\mathrm{O}$ que importa diante desse quadro que foi exposto? A vida sempre exige outras potencialidades, não se trata de entrar em um pessimismo e nem em uma euforia sem limites, mas de buscar maneiras de resistir à pulverização do agora, a miserabilidade de um presente afogado nos limites da negação da cultura e da tradição. Ora, não é pensar nostalgias elementares e nem certas utopias extremas, mas pensar o nosso tempo com cores vivas, a vida que se apresenta, sendo ela a única que se tem para ser movimentada entre essas trincheiras. Como diz Pelbart: "não refugiar-se em algum paraíso pretérito ou futuro, de modo nostálgico ou embevecido, mas estar atento às urgências deste nosso presente, desta nossa vida, desta nossa guerra, destes devires revolucionários que se gestam no nosso dia a dia" (2011, p. 214).

2.

Foi o povo que deu o nome - MARUJADA Aquela manifestação de gratidão...

Pois, ela, representa a nossa tradição! As marujas, velhinhas, já não dançam mais, Agora, são mocinhas de fôros sociais Que vestem a indumentária e vão à rua bailar... Benedito Cezar Pereira

\footnotetext{
${ }^{1}$ Professora do Instituto Federal de Educação do Pará-Bragança. E-mail: helanesantos@yahoo.com.br

2 Professora da Universidade Federal do Pará/Instituto de Educação Matemática e Científica. E-mail: mrdbrito@hotmail.com.
} 
Alastrar o desejo, a alegria, a dança e proliferar sentimentos, formas de culturas, agenciar gerações para pensar espaços de afetos, de encontros, de aprendizados vitais, movimentar o corpo por entre ações inventivas, sair das velhas categorias que dizem: isso é cultura! Isso não é cultura! Isso é relevante para a vida, isso não é relevante para a existência! Deixar um pouco o código, a lei que limita a fala, a expressão corporal, investir na positividade, multiplicar os espaços fora da tristeza, deixar a cultura popular liberar a sua ação política para além da norma verdadeira, sair do espírito de julgamento. Deleuze e Guattari (2010) convocam o corpo, a vida para dançar a dança do desejo, da amizade e dos afetos.

É com essa vitalidade que acontece a festa da Marujada, uma manifestação cultural que ocorre há mais de duzentos anos no município de Bragança ${ }^{3}$, nordeste do Pará. Surgiu quando os senhores brancos, atendendo ao pedido de seus escravos, permitiram a organização de uma Irmandade e a primeira festa em louvor a São Benedito. Em sinal de reconhecimento, os negros foram dançar em frente a casa de seus benfeitores para agradecê-los (MIRANDA, 2015). Essa manifestação da alma do povo resiste às festas de final de ano novo regado pelo capital e pela a euforia dos presentes. Atualmente, ela mantém sua vivacidade como na percepção de Serra Netto (2015, p. 378),

O som das castanholas tocadas pelos marujos aliada a rabeca, ao pandeiro, a dança do "retumbão" dão vida ao colorido que se apresenta na corporeidade e em alguns pontos específicos da cidade... Esses elementos se apresentam em uma espécie de sinestesia onde os sentidos se confundem e nos fazem embarcar em uma viagem imaginária onde o tempo cronológico é suprimido e somos remetidos ao tempo imemorial - [...] emerge em vários pontos da cidade, seja nos gestos, no som ou no corpo das pessoas que compõem este belíssimo ritual.

Há todo um sincretismo nesta festa, caracterizada pela delimitação do espaço sagrado e do profano com alguns ritos como a dança, a cavalhada, a esmolação e a procissão. A dança, executada por marujos e marujas, é um dos principais acontecimentos da festa, alguns ritmos são peculiaridades da Marujada, principalmente o retumbão ${ }^{4}$. A cavalhada também é um dos eventos da Festividade de São Benedito, lembra o combate entre cristãos e mouros nas batalhas medievais por territórios sagrados. É composta apenas por cavaleiros e suas montarias, que disputam argolinhas nas cores azul e vermelha. Vence quem conseguir alcançar o maior número delas. Outro ritual da festa é a esmolação feita pelas comitivas de esmoleiros trajando opas ${ }^{5}$ de cores determinadas, que carregam uma imagem do santo, instrumentos musicais, bandeiras e executam um conjunto de canções orantes em latim, ladainhas e folias de homenagem a São Benedito (NONATO DA SILVA, 2006). A procissão agrega milhares de pessoas que se movimentam pelas ruas da cidade no dia 26 de dezembro, proporcionando uma onda gigante colorida pelos chapéus de marujas e marujos.

\footnotetext{
${ }^{3}$ Bragança é uma das cidades mais antigas do Estado Pará, situada às margens do Rio Caeté, distante 208 km da capital, Belém. Sua origem é datada de 8 de Julho de 1613, a partir da expedição francesa de Daniel de La Touche, essa região era habitada por indígenas Tupinambás.

${ }^{4}$ A característica da Marujada é a dança, um lundu com o nome de retumbão, que evoluiu para a dança da Marujada, como sendo celebrada desde a época das navegações em Portugal, vinda para o Brasil, transformandose num bailado popular, provavelmente entre fins do século XVIII e início do XIX, com um toque de erudição, recebendo a influência de poetas alfabetizados para o alcance de um nome, como "Chegança de Marujos" (NONATO DA SILVA, 2006).

5 Tipo de vestimenta utilizada pelos rezadores.
} 
3.

...Pés descalços dançando e bailando,

Marujada no barracão...

Júnior Soares

Os pedaços de imanência atravessam os pés daqueles que dançam a Marujada numa mistura de sagrado e profano, pois além da procissão, missa e outras formas de manifestações religiosas, destacam-se as danças entoadas com instrumentos musicais. Em tempos de virtualidade, essa manifestação da cultura popular convoca as pessoas para um campo de sensibilidade que atravessa toda uma geração de indivíduos.

Os pés dançantes, em seus compassos... As mulheres vestidas com suas saias longas, rodadas, seus chapéus rodeados de fitas coloridas penduradas compõem toda uma variação do corpo que dança, que espanta a tristeza, a dor... as crianças seguem o ritmo de seus pais, seus avôs, seus tios... As mulheres dançam, espantam uma vida triste... nesse acontecimento que ora carrega seu corpo, a cidade fica em festa... Todos os dançarinos, sejam homens e mulheres, estão com os pés descalços, como se necessitassem sentir o próprio som da terra...

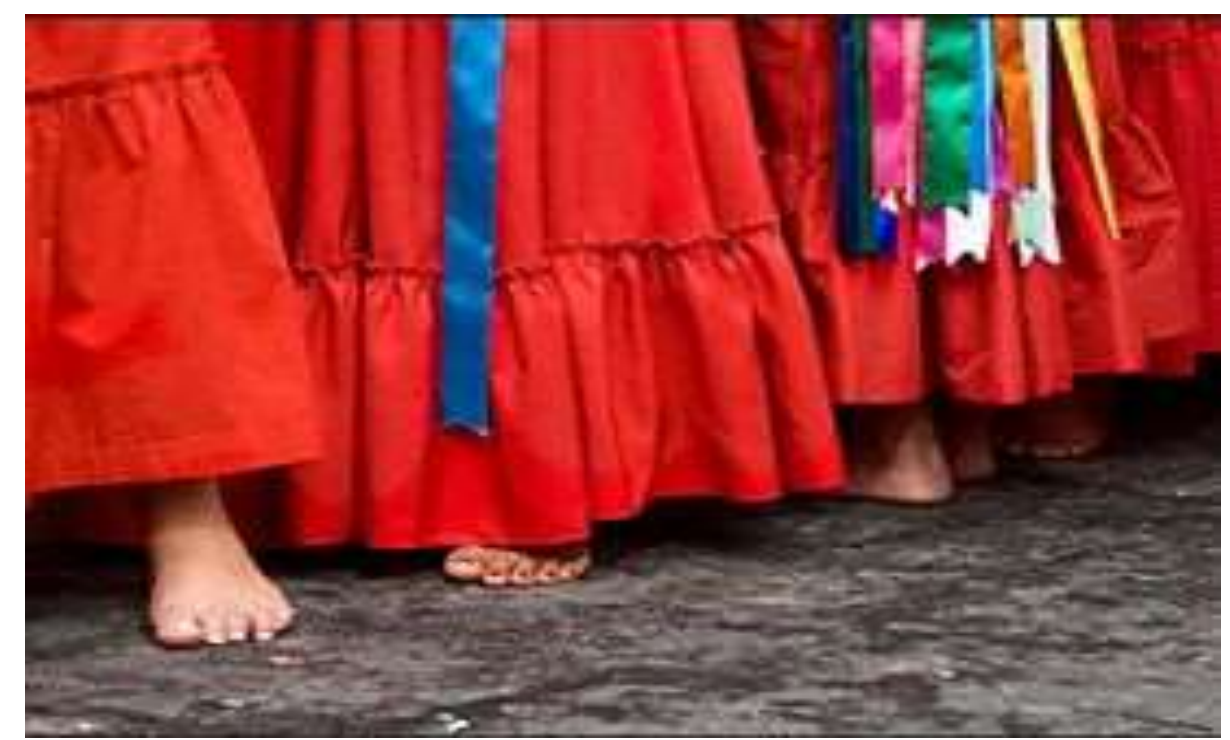

Fonte: Fotografia de Manoel Neto-Marujada de Bragança-Pará, 2008.

4.

A festa é ritualizada por toda uma composição de cores, de sons, de vida, de iluminação. A igreja de São Benedito entrelaça essa manifestação tocando seus sinos como se quisesse acordar o povo para uma nova aurora.

A Marujada, laica e religiosa, profana e sagrada, escapa da modelação esperada e desejada pela romanização, mesmo estando às portas da Igreja enquanto instituição e espaço físico. Espaço sagrado com apropriações profanas, o largo de São Benedito pode ser encarado como a lente por onde se observa a cidade em movimento (NONATO DA SILVA, 2006). A Igreja, o largo e o arraial são janelas para a visualização uma cidade composta por seus habitantes, suas ações, sentimentos e seus movimentos mais particulares. 


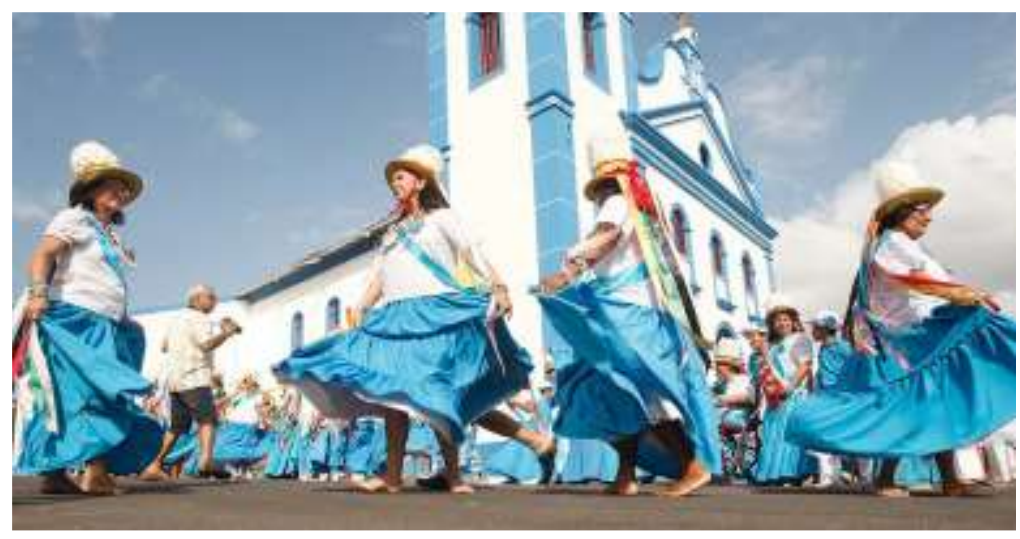

Fonte: Miranda (2015).

\section{5.}

As fitas coloridas parecem ondas de alegria, amarradas nos pulsos das pessoas ou ancoradas nas hastes transportadas pelos vendedores ambulantes, elas balançam como se vibrassem cortas sonoras.

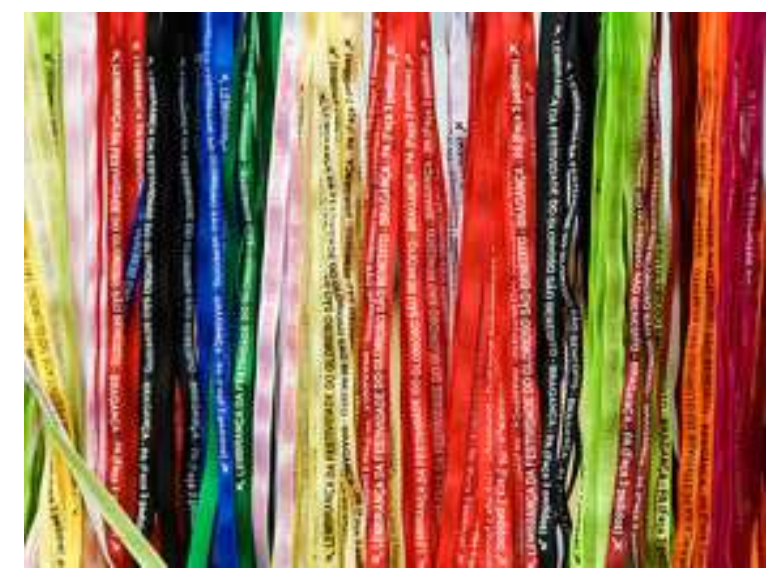

Fonte: Fotografia de Manoel Neto-Marujada de Bragança-Pará, 2008.

Para alguns, as fitas são apenas uma lembrança da festividade, mas para outros a possibilidade de ter três pedidos atendidos, que podem ser feitos antes de amarrá-las, os quais podem se realizar até que ela seja desamarrada após seu desgaste. Além da proliferação de cores, as fitas coloridas também fazem proliferar sensações, desejos, segredos, pensamentos... vida!

6.

Vem vestindo azul ou vermelho carmim na festa No barracão dança xote, mazurca e chorado Nos duzentos anos de louvação Mas fico mesmo encantado Quando dança retumbão. Júnior Soares e Edu Filho 
São as Mulheres, chamadas de Marujas, especialmente a capitoa, que com seu parceiro, iniciam a dança no meio do salão dando prosseguimento a roda de dança. Há todo um colorido das vestimentas, os homens também se vestem a caráter proliferando suas cores, suas ondas de sons, como os das castanholas, utilizadas como instrumentos sonoros pelos marujos na dança do retumbão.

Essa imagem mostra aquilo que os moradores chamam de barracão da Marujada, lá o corpo é envolvido pelos sons dos tambores, cuícas, pandeiros, violas, cavaquinhos, violinos e rabecas.

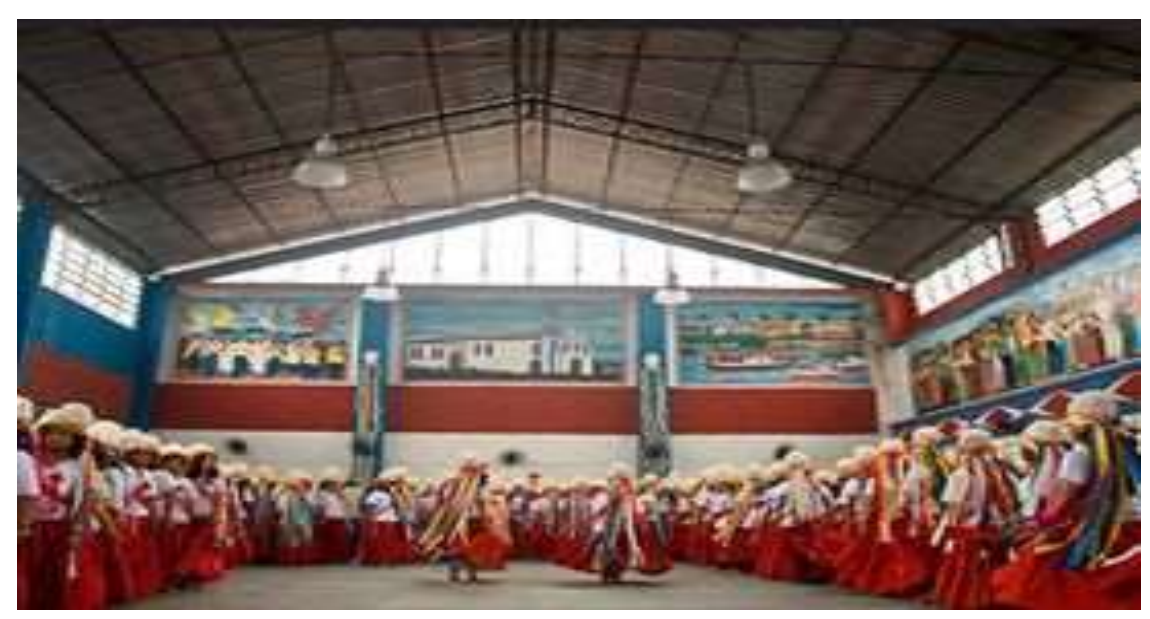

Fonte: Fotografia de Manoel Neto-Marujada de Bragança-Pará, 2008

Os músicos tocam vários ritmos, como Retumbão, Chorado, Mazurca, Valsa e Xote. Os corpos vão girando, as cores vão se movimentando, compondo uma espécie de universo cultural de alegria do povo.

A dança da marujada é a parte profana da festa. Segundo historiadores, está ligada ao culto de São Benedito desde os seus primórdios. Ainda hoje prevalece na manifestação e segue um ritual composto por: retumbão, chorado, nas quais se sente o ritmo do batuque negro; e mazurca e xote, caracterizado como danças de salão europeias. Essa união de estilos musicais distintos se chama suíte, termo utilizado na música erudita. As músicas que compõem a suíte da marujada são instrumentais (MORAES et al., 2006, p. 60).

Segundo Bordallo da Silva (1981), o retumbão é a dança mais tradicional da Marujada, sua coreografia obedece a uma "fuga bruscamente interrompida". O Chorado se constitui numa variação do retumbão, dançado sob uma maior suavidade e lentidão dos passos e do tom musical por apenas um casal, livremente escolhido e com alternância a cada final de dupla. A Mazurca é dançada por casais cujos corpos são dispostos lateralmente, como num abraço de lado, sendo caracterizado pela rapidez, balanço, sacolejo que, na forma de um círculo, rodopiam pelo salão. É uma dança sensual, que expõe o sentimento, atingindo, inclusive, um clímax, que se dá na aceleração do ritmo pelos tocadores. A Valsa, incorporada à Marujada pelos brancos, que a executavam nos salões de bailes em Bragança assumindo certa variação no que tange à forma, opõe-se ao ritmo frenético da Mazurca, por tons lânguidos. $O$ Xote foi incorporado à manifestação pelos aristocratas senhores de escravos. 


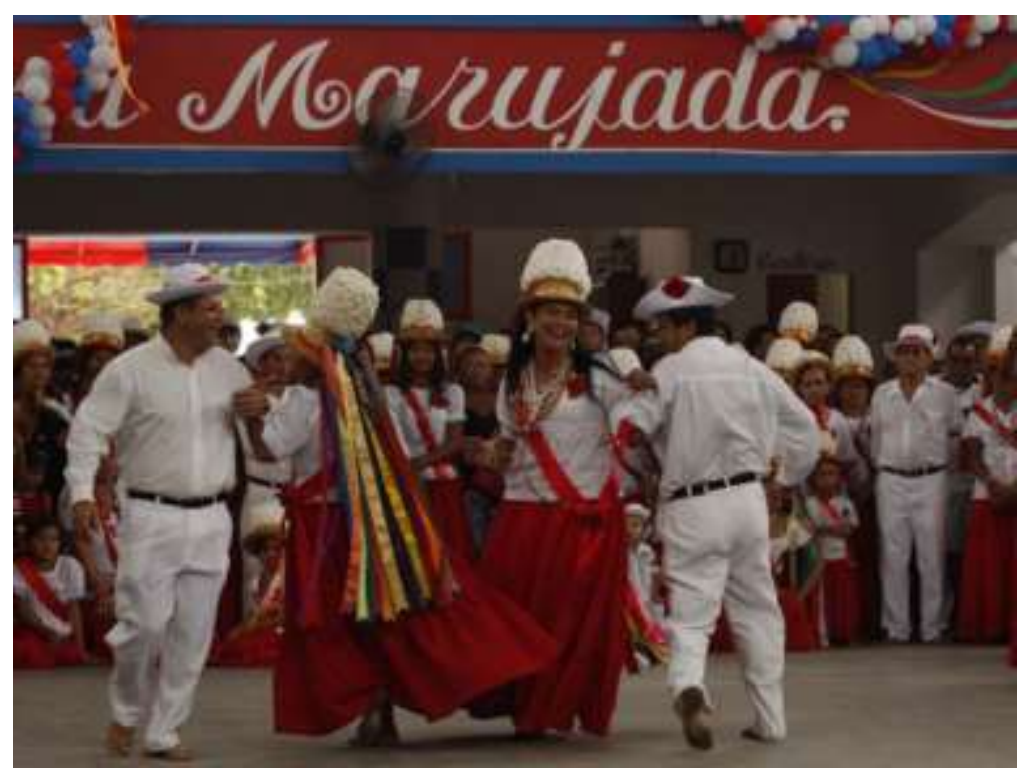

Fonte: Google imagens.

Um ritual que segue gerações, que insiste e resiste ao tempo presente, do tempo imediato. Uma fotografia movente daquilo que é registrado no corpo, mas sem ressentimento, sem dor...A beleza dessa manifestação da cultura popular é a ritualização persistente, a fé e o profano estão mesclados, o povo nesse dia faz uma festa em nome da alegria... Se o nosso milênio comporta tantas desorientações, o povo bragantino mergulha o seu corpo na carne para fazer da vida uma experimentação de alegria e não da tristeza.

\section{7.}

Senhoras preparam seu corpo para a festividade, unhas pintadas, rosto maquiado, fitas enfeitando a indumentária, cores vivas por todo o corpo, vários colares, anéis, pulseiras, acessórios que as adornam para deixá-las mais coloridas.

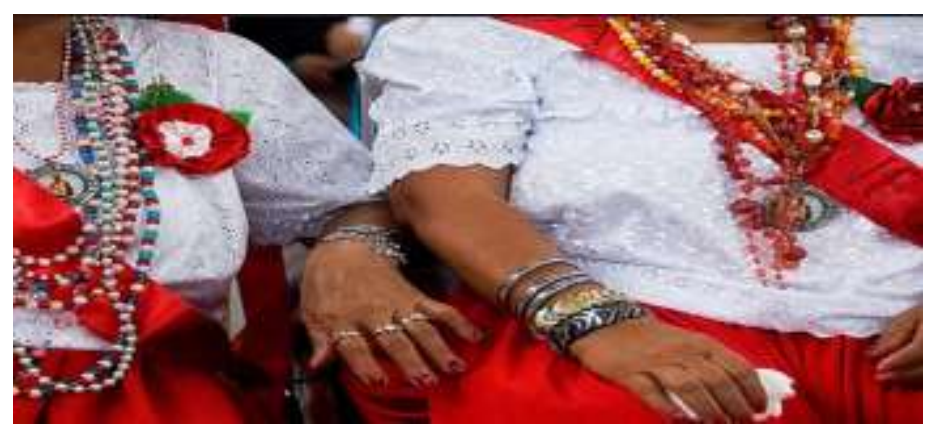

Fonte: Fotografia de Manoel Neto-Marujada de Bragança-Pará, 2008

Um dos acessórios mais importantes para as marujas é o chapéu, este é forrado de tecido dourado com as laterais bordadas em paetês e pedras brilhosas e na parte de cima aplica-se pena de pato que são preparadas para que fiquem bem branquinhas, na parte traseira são coladas doze fitas coloridas (MIRANDA, 2015). Durante a procissão, quando as marujas seguem o cortejo enfileiradas, belas imagens de cores e nuvens (formadas pelas penas brancas na parte superior dos chapéus) parecem se deslocar pelas ruas estreitas da cidade. Ondas de alegria! 


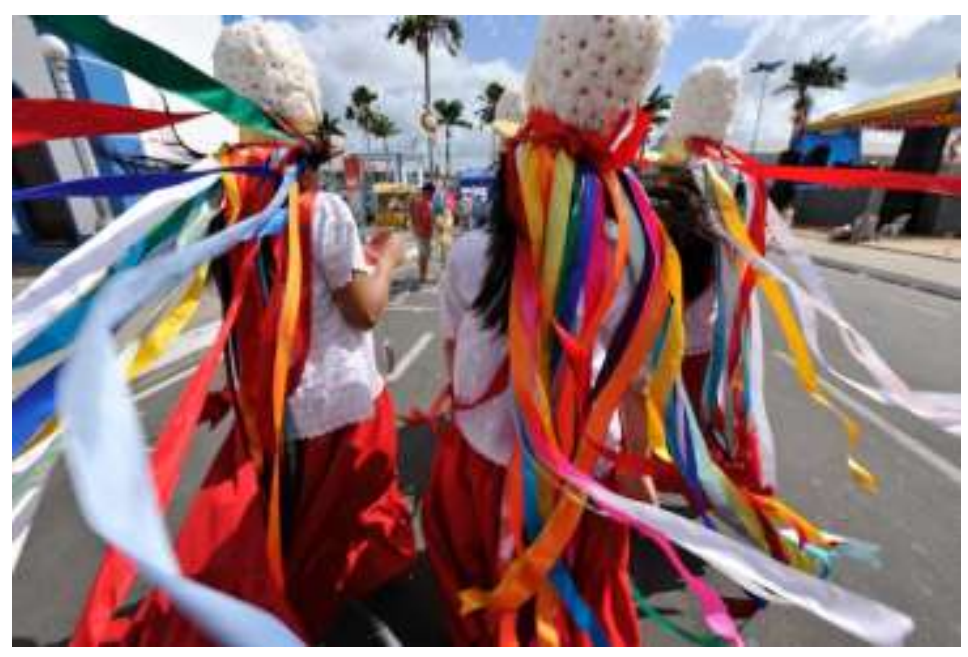

Fonte: Google imagens.

8.

Há toda uma preparação para a vida, pedaços de imanências que formam redes, conexões de transbordamentos... corpos derivam na roda da Marujada. São pequenos pontos, pequenas ondas, pequenos movimentos desenrolados pela dança Bragantina, que leva o contágio cultural para as crianças, para os jovens... a dança vai multiplicando as gerações de Marujos e Marujas... Diríamos como Deleuze, há um agenciamento do desejo que corre os corpos desses dançarinos que evocam as energias misteriosos, como se para viver fosse necessário entrar em certos mistérios... vidas insondáveis para poder se dispor do presente sem tanto medo, sem tanto horror. O que o corpo solicita? Ele parece solicitar uma vitalidade, e os rituais que compõem a Marujada de Bragança, parecem fazer a vida vibrar por seus movimentos, suas danças, suas cores e seus sons...Um acontecimento que faz convocação para a alegria e para a tradição desta cidade.

\section{Referências}

BORDAllo DA SILVA, A. Contribuição ao Estudo do Folclore Amazônico na Zona Bragantina. Belém: Falangola Editora, 1981.

DELEUZE, G.; GUATTARI, F. O anti-édipo: capitalismo e esquizofrenia. São Paulo: Ed. 34, 2010.

MIRANDA, R. D. S. Religiosidade, Experiências e Saberes: evidenciados na festa da Marujada do Glorioso São Benedito em Bragança Pará. Anais dos Simpósios da ABHR, 14. 2015.

MORAES, M. J. P. da C. de; ALIVERTI, M. J.; SILVA, R. M. M. da. Tocando a Rabeca. Belém: IAP, 2006.

NONATO DA SILVA, D. B. R. Os Donos de São Benedito: convenções e rebeldias na luta entre o catolicismo tradicional e devocional na cultura de Bragança, século XX. Dissertação. Belém. Programa de Pós-Graduação em História Social da Amazônia. UFPA, 2006.

PELBART, P. Vida capital: ensaios de biopolítica. São Paulo: Iluminuras, 2011. 
SERRA NETTO, H. F. da. "O milagre das rosas vermelhas": corporalidade, fotografia e sacralidade na marujada de Bragança - Pará. Iluminuras, Porto Alegre, v. 16, n. 37, p. 378388, jan/jun. 2015. 